\title{
Urban Flood Modeling of a Partially Separated and Combined Drainage System in the Grefsen Basin in Oslo, Norway
}

\author{
Hong Li, ${ }^{1}$ Hongkai Gao, ${ }^{2}$ Yanlai Zhou, ${ }^{1}$ Ina Storteig, ${ }^{1}$ Linmei Nie, ${ }^{3}$ Nils Roar Sælthun ${ }^{1}$ and Chong-Yu Xu ${ }^{1}$ \\ ${ }^{1}$ University of Oslo, Oslo, Norway; ${ }^{2}$ East China Normal University, Shanghai, China; ${ }^{3}$ Centre for Sustainable Development and Innovation of
}

Water Technology, Oslo, Norway.

\begin{abstract}
The Storm Water Management Model (SWMM) has been globally used for stormwater management. However, the calibration and evaluation of SWMM for historical rainfall-runoff events in partially separated and combined drainage systems is rarely reported in Norway. In this study, we employed SWMM for the Grefsen catchment in Oslo, Norway. The main problem in the Grefsen basin is combined sewer overflow. We calibrated the model parameters based on 32 rainfall-runoff events and evaluated the calibrations using four indicators: Nash-Sutcliffe efficiency, percentage bias, and continuity errors for runoff and flow. There were 32 successful calibrations using Nash-Sutcliffe efficiency, 30 successful calibrations using percentage bias, 32 successful calibrations using continuity error runoff, and four successful calibrations using continuity error flow. SWMM can well simulate the dynamics of hydrological and hydraulic systems in this catchment. Among the 124 validations, there were 88 successful simulations using Nash-Sutcliffe efficiency, 35 successful simulations using percentage bias, 124 successful simulations using continuity error for runoff, and 62 successful simulations using continuity error for flow. The results show that percentage bias and continuity error flow are the critical indicators for model calibration. This study reveals the large uncertainty caused by calibration and validation criteria, and highlights the importance of considering model computation error.
\end{abstract}

\section{Introduction}

Urbanization is a global trend. Since 2009 , more than $50 \%$ of the world population has been living in urban or semiurban areas according to World Population Prospects 2019 from the United Nations (2019). By the year 2030, the urban population will exceed $80 \%$ of the total world population (Salvadore et al. 2015). In developed countries, the degree of urbanization is even higher. For example, approximately $87 \%$ of the population in Sweden (Statista 2019) and 82\% in Norway (SSB 2018) are already living in urban areas.

One major problem of urbanization is the increasing magnitude and frequency of urban flooding. Impermeable surfaces reduce infiltration and increase flow velocity. With climate change, especially increases in storm intensity and other extreme events, urban flooding increases and economic damages and other consequences become severe (Nie et al. 2009; Velasco et al. 2012).

Urban flooding is a great threat to the security of residents and causes huge economic loss. In Norway, the main problem of urban flooding is basement flooding (Lindholm et al. 2006; Nie 2016). In Oslo, insurance claims for urban flood-related damages, mainly basement flooding, from 2008 to 2014 were $>97$ million NOK (VAV 2016) and approximately $30 \%$ of the damage events are additionally not claimed (Finsland 2019). Urban flooding is a major route for transporting urban pollutants to rivers and oceans (Nie et al. 2011; Åstebøl and Hvitved-Jacobsen 2006).

Combined sewer overflow (CSO) is another threat to the urban environment and ecosystem. A combined sewer system (CSS) is quite common in many countries and cities (Salvadore et al. 2015). In Oslo, the sewer system is $2250 \mathrm{~km}$ in total, and $>36 \%$ of the sewer system is CSS (Holmberg 2019). The excess flow, containing untreated sewage, discharges directly into streams and other water bodies. CSO may include high levels of toxic chemicals and destroy the local ecosystem. In the United States, 860 communities have combined sewer systems, serving about 40 million people (Wikipedia 2021) and there are currently about 800 CSO outfalls in New York State (Department of Environmental Conservation 2021).

Urban hydrological modeling is a useful and important tool for urban flood simulation, protection and management. In recent years, modeling tools have improved significantly due to the development of computation techniques and the availability of high-resolution data. However, there is no universal methodology for urban hydrological modeling at the catchment scale due to the great heterogeneity of urban areas and the multiplicity of interactions between the urban structure and the water system (Li et al. 2020, Salvadore et al. 2015, Skaugen et al. 2020). The

Li, Hong, Hongkai Gao, Yanlai Zhou, Ina Storteig, Linmei Nie, Nils Roar Sælthun, and Chong-Yu Xu. 2022. "Urban Flood Modeling of a Partially Separated and Combined Drainage System in the Grefsen Basin in Oslo, Norway" Journal of Water Management Modeling 30: C480 https://doi.org/10.14796/JWMM.C480 (C) Li et al. 2022 www.chijournal.org ISSN 2292-6062 
Storm Water Management Model (SWMM; Rossman 2015) and the Model for Urban Sewers (MOUSE; Lindberg et al. 1986) are the most widely used models for stormwater management and urban drainage planning. SWMM is more often used for scientific purposes than MOUSE because it is open source software and is free for use worldwide. SWMM provides a good balance between the level of detail required to describe physical processes and computational parsimony (Niazi et al. 2017). However, applications of the model in Norway are rarely reported in international scientific journals because the MOUSE model has a major market share in Norway. Existing literature is limited to the use of SWMM to reproduce rainfall-runoff for grey and green roofs and to transfer parameters among different sites (Johannessen et al. 2019; Hamouz and Muthanna 2019; Russwurm et al. 2018). The main purpose of this paper is to examine for the first time the application of SWMM in a Norwegian urban catchment to simulate historical events. Figure 1 gives an overview of the workflow.

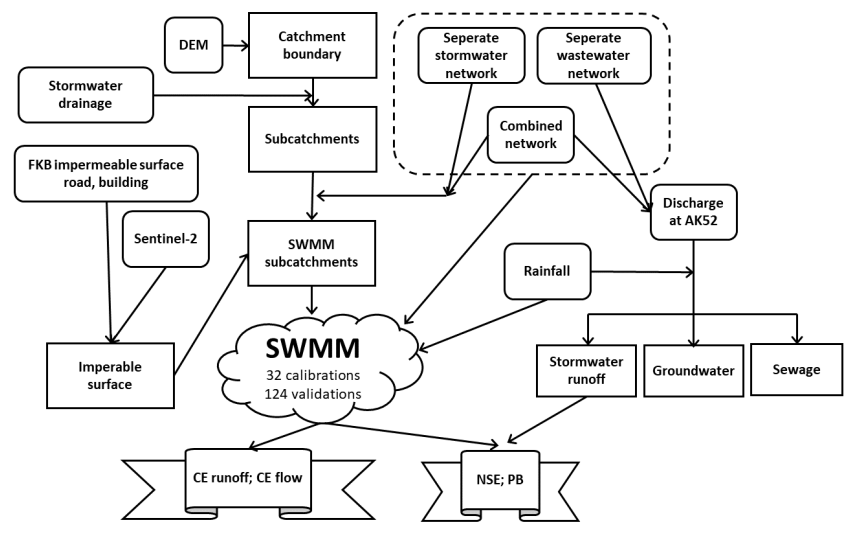

Figure 1 Flowchart of this study.

\section{Study area and data}

\subsection{Study area}

Oslo is the capital city of Norway and the country's economic and governmental center. Grefsen is a residential area in the northern part of Oslo. The Grefsen catchment is approximately $1.3 \mathrm{~km}^{2}$ (Figure 2) with a population of $~ 5000$ inhabitants. Impermeable surfaces, mainly buildings and roads, account for $22 \%$ of the catchment area. The eastern part of the catchment is flat and densely built up, and most residents live there.

The sewer networks in the study catchment contain both separated and combined systems. The combined sewage system covers the southwest of the catchment and the separated sewage system covers the northeast of the catchment. The CSOs occur at the outfall, weir AK52 at inspection chamber 161143 as identified in the archives of Oslo Water and Sewage Agency. A stormwater weir is at the side of the combined weir. When the water depth in the combined weir exceeds $40 \mathrm{~cm}$, sewage overflows through the stormwater pipes into the Akerselva River. In 2017, CSOs lasted for a total of 5 h 23 min (Storteig 2019).

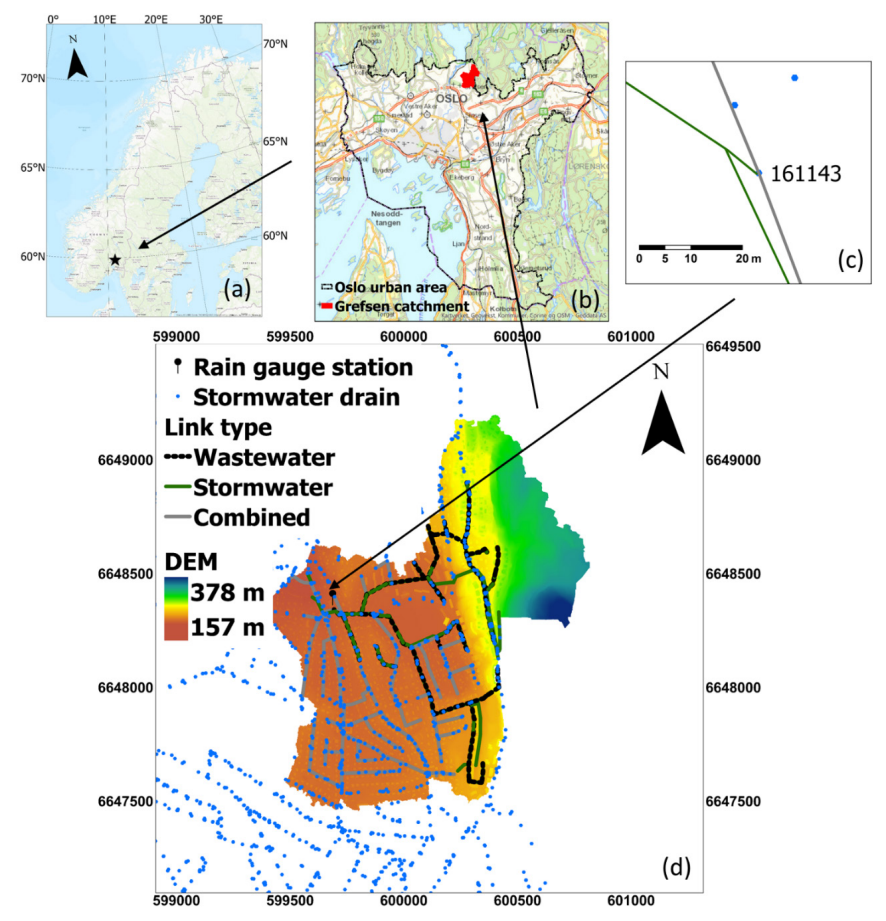

Figure 2 Location of Grefsen catchment and the outfall: (a) location of Norway and Oslo; (b) location of the Grefsen catchment in urban Oslo; (c) location of the outfall; (d) digital elevation model and the sewage system, where wastewater pipes partly overlap with stormwater pipes.

\subsection{Data}

The data requirements of SWMM vary according to the model processes and setup. For example, the temperature is required for the calculation of snowmelt and evaporation but is not necessary for short term flood simulation. In this study, we simulated discharge at an outfall for 32 rainfall-runoff events in three years, 2010, 2016 and 2017. The longest duration event lasted only $\sim 2 \mathrm{~d}$ and therefore evapotranspiration was not important. Thus we used only rainfall data as climate inputs. Other types of data including information about the drainage system and hydrological characteristics of the subcatchments were necessary inputs. Discharge measurements at outfall AK52 were used for model calibration.

Rainfall data were measured at the Kjelsås rain gauge. The rain gauge was a NIVUS RM 202 (Nivus 2015) pluviometer. The rain gauge recorded the time when $0.1 \mathrm{~mm}$ precipitation was detected. The raw data were aggregated to a time step of $5 \mathrm{~min}$.

The discharge was calculated according to velocity and depth, which were measured by automatic sensors and an ASS FlowShark Triton flow monitor. The accuracy of the discharge was dependent on the accuracy of velocity and depth measurements. Sometimes, waste adheres to the sensors and causes discharge disturbances, mainly in low flow periods. 
The data for hydraulic inputs, junctions and conduits were obtained from the Oslo Municipality Water and Sewage Administration.

The surface characteristics of the subcatchment included elevation, slope, and percentage of impermeable surface. The source of elevation was a digital map at a spatial resolution of $0.5 \mathrm{~m}$. It was a hybrid product of two terrain data sets. For the Oslo city area, the terrain map was extracted from lidar data obtained in the summer of 2014 (Mæhlum 2014). For the forest and hilly area surrounding the city area, the terrain was interpolated from elevation contours from the Norwegian Mapping Authority.

The impermeable surface was a combination of land surface type images and local maps. The land surface type image was classified using the Sentinel-2 satellite data (Stange 2017) as shown in Figure 3. The spatial resolution was $10 \mathrm{~m}$. This spatial resolution cannot represent small roads or buildings, so roads and buildings from the Norwegian common map database (FKB; Norwegian Mapping Authority 2005) were integrated. The satellite land surface type map and the FKB road and building maps were resampled by the nearest neighbor method to $0.5 \mathrm{~m}$ raster data and eventually rasterized.

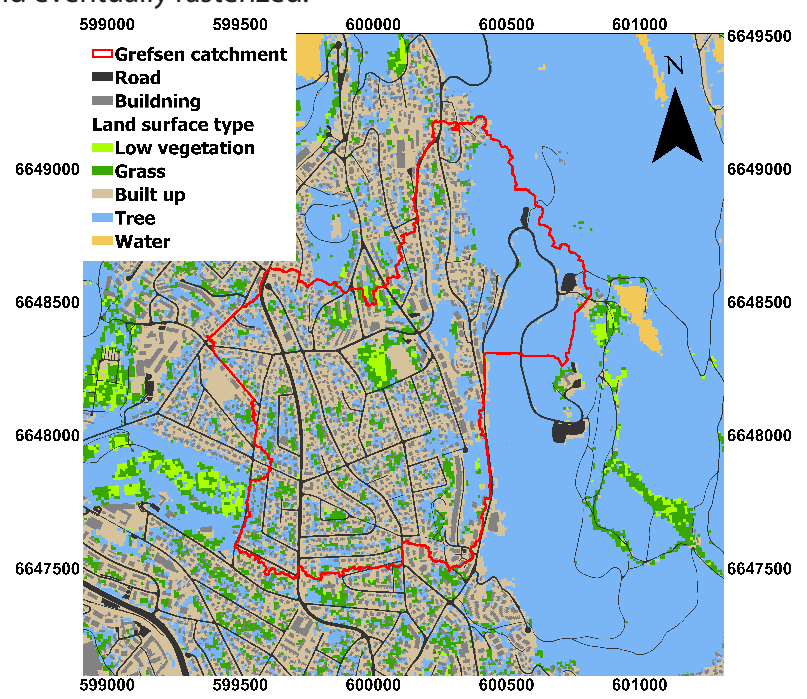

Figure 3 Land surface including roads, buildings and land surface classification from the Sentinel-2 satellite.

\section{Methods}

\subsection{SWMM}

The Storm Water Management Model (SWMM) is a combined hydrologic (rainfall-runoff) and hydraulic (pipe routing) model (Lager et al. 1971; Digiano and Mangarella 1975; Rossman 2015).

In the hydrological module of SWMM, the hydrological response unit is the subcatchment, which is further divided into three types of subareas: pervious, impervious with depression storage, and impervious without depression storage. The three subareas share the same subcatchment characteristics and inputs, such as slope, width, and precipitation and evaporation rates. Runoff generation occurs independently in each subarea, but areas can route into each other before all runoff reaches the same subcatchment outlet.

In terms of hydrological processes, SWMM can simulate the processes of evaporation, rainfall-runoff, snowmelt, and groundwater flow. For the sewerage system, SWMM offers several types of nodes and links according to the modeling objective. The nodes represent point objects in the sewage system (e.g. access chambers, junctions between channels, and weirs). The links represent connections between nodes (e.g. pipes and channels). Three methods are available for flow routing in the links: steady flow, kinematic wave, and dynamic wave. More information about SWMM is available from the webpage https://www.epa.gov/ water-research/storm-water-management-model-swmm.

\section{Equations and parameters}

There are many equations and parameters in SWMM. Here we give a detailed description of the overland flow because it is important for sustainable stormwater management and the parameters are very sensitive to discharge.

SWMM conceptualizes a subcatchment as a rectangle with uniform slope $S$ and width $W$. The water depth $d$ of the subcatchment is a function of rainfall input and discharge output.

$$
\frac{\partial d}{\partial t}=i-e-f-q
$$

where:

$$
\begin{aligned}
t & =\text { time, } \\
i & =\text { rate of rainfall plus snowmelt, } \\
e & =\text { surface evaporation rate, } \\
f & =\text { infiltration rate, and } \\
q & =\text { runoff rate. }
\end{aligned}
$$

Assuming the overland flow across the subcatchment surface is uniform, the Manning equation can be used to express the runoff volumetric rate $Q$ as:

$$
Q=\frac{1}{n} S^{1 / 2} R_{X}^{2 / 3} A_{X}
$$

where:

$$
\begin{aligned}
Q & =\text { discharge from subcatchment, } \\
n & =\text { surface roughness coefficient, } \\
S & =\text { subcatchment slope, } \\
A_{x} & =\text { area of discharge cross section, } A_{x}=W\left(d-d_{s}\right), \\
R_{x} & =\text { hydraulic radius, } R_{x}=d-d_{s^{\prime}} \text { and } \\
W & =\text { subcatchment width, } \\
d & =\text { overland flow depth, } \\
d_{s} & =\text { depression storage depth, } \\
A & =\text { subcatchment area. }
\end{aligned}
$$

The runoff flow rate per unit of surface area $q$ is described by:

$$
q=\frac{1}{A \cdot n} W S^{\frac{1}{2}}\left(d-d_{s}\right)^{\frac{5}{3}}
$$


The variables are as defined above. For details, see Rossman and Huber (2016).

\subsection{Catchment delineation}

The catchment is the area in which hydrological processes occur. The delineation of the catchment boundary is usually based on the terrain. However, the terrain is significantly changed by human activities in urban areas, so it is necessary to use a high-resolution digital elevation model of the urban area to represent terrain as modified by urban infrastructure. The sewage system affects water to flow through the subcatchment. It collects surface runoff into the subsurface pipe system, transports the water to downstream recipients or wastewater treatment plants (WWTP). The flow follows the pipe rather than the terrain. Therefore, it is important to be careful in delineating the catchment boundary.

We delineated the area of the catchment to outfall AK52 based on a $0.5 \mathrm{~m}$ lidar terrain model using a multiflow direction algorithm that diverts the water flow downstream in proportion to the slopes of all the downstream cells created by the software Geographic Resources Analysis Support System (GRASS) GIS, version 7.4.1. Additionally, we manually checked to see if the sewage system imported or exported runoff across the catchment boundary.

\subsection{Subcatchment delineation}

To run SWMM, the catchment was further divided into subcatchments. Normally surface runoff ends in a street drain where it enters the piped drainage system. However, street drains were not identified in the drainage system descriptions. Therefore the outlets of the stormwater subcatchments were assigned to their nearest stormwater or combined access chambers by the nearest neighbor method. The subcatchments were aggregated according to the pipe system to reduce computing demand. Subcatchments having the same downstream access chambers were merged as big subcatchments. Aggregation began at the smallest subcatchment and continued until all the subcatchments that shared the same outlet were aggregated into one big subcatchment. Eventually, there were nine subcatchments.

\section{Runoff components}

Outfall AK52 is a combined access chamber and discharge measurements included wastewater and stormwater runoff as well as groundwater leakage. We modeled only stormwater runoff and therefore wastewater and groundwater components were removed from the observed discharge to calibrate SWMM.

Groundwater and wastewater consist of dry period discharge. Groundwater leakage is a relatively stable runoff component and does not fluctuate because of rainfall or water drainage. We assumed the daily minimum discharge of dry periods to be the magnitude of groundwater. For days without data, groundwater was linearly interpolated from other days with data.

Wastewater discharge is the remaining component of the dry period flow. The wastewater time series were aggregated into patterns: monthly, daily, hourly and weekend. The wastewater time series were generated according to the SWMM method: Inflow $=($ Average Value $) \times($ Pattern 1, monthly $) \times($ Pattern 2, daily $) \times$ (Pattern 3, hourly or weekend). The average value was calculated from the SSB municipal water supply (2019) and the population in the study area.

\subsection{Model calibration and evaluation criteria}

Model calibration was performed using the SRCT tool in PCSWMM (2020). SRCT can run SWMM in parallel with defined parameter uncertainties and find parameter sensitivities (PCSWMM 2020). The user has to verify the model to get the true model efficiency. It is common to run the SRTC tool several times to achieve a good calibration. The goodness of calibration can be judged by a visual comparison of the measurement data and the modeling results, or by numerical indicators. In this study, the most reliable measurements were the discharge data at the outfall AK52. We used two numerical indicators, Nash-Sutcliffe efficiency (NSE) and percentage bias (PB). We adopted NSE > 0.5 and $P B<25 \%$, which were used as criteria for the acceptable model performance of urban runoff simulations by Johannessen et al. (2019). Additionally, continuity errors (CE) in the model computation were used as additional indicators for both the hydrology (CE runoff) and hydraulics (CE flow). The continuity errors are not conventional calibration indicators, but they are dependent on the model parameters. The model user has to make sure that the continuity errors are in an acceptable range, which indicates SWMM is stable. According to Farah (2009), a 10\% continuity error is tolerable, both for $C E$ runoff and $C E$ flow, and we adopted these values as our criteria. The equationsof the indicators are:

$$
N S E=1-\frac{\sum_{t=1}^{T}\left(Q_{m}^{t}-Q_{0}^{t}\right)^{2}}{\sum_{t=1}^{T}\left(Q_{0}^{t}-\overline{Q_{0}}\right)^{2}}
$$

where:

$$
Q_{m}=\text { the modeled runoff series }
$$

$Q_{0}=$ the observed runoff series

$$
P B=\frac{\sum_{t=1}^{T}\left(Q_{m}^{t}-Q_{0}^{t}\right)}{\sum_{t=1}^{T} Q_{0}^{t}} \times 100
$$

where:

$$
Q_{m}=\text { the modeled runoff series }
$$

$Q_{0}=$ the observed runoff series

$$
C E=100 \times\left(1-\frac{\text { total output water }}{\text { total input water }}\right)
$$

\section{Results}

\subsection{Rainfall-runoff events}

In total, there were 32 rainfall-runoff events (Table 1) available for model evaluation. SWMM was calibrated using every event so there were 32 calibrations. There were 14 events in 2010, 16 
events in 2016, and 2 events in 2017. There were 9 events in June, 8 events in July, 12 events in August, and 3 events in September. The average duration of the events was $11.5 \mathrm{~h}$; event duration ranged from $135 \mathrm{~min}$ to $3150 \mathrm{~min}$. The maximum rainfall ranged from $0.4 \mathrm{~mm} / 5 \mathrm{~min}$ to $5.2 \mathrm{~mm} / 5 \mathrm{~min}$.

Table 1 Events overview.

\begin{tabular}{|c|c|c|c|c|c|c|c|}
\hline Name & Start & end & $\begin{array}{l}\text { Mean } P \\
(\mathrm{~mm} / \mathrm{h})\end{array}$ & $\begin{array}{c}\max P \\
(\mathrm{~mm} / \mathrm{h})\end{array}$ & $\begin{array}{c}\text { mean Q } \\
(\mathrm{L} / \mathrm{S})\end{array}$ & $\begin{array}{c}\max Q \\
(\mathrm{~L} / \mathrm{s}) \\
\end{array}$ & $\begin{array}{c}\text { duration } \\
(\mathrm{min})\end{array}$ \\
\hline event01_1 & $20100608 \mathrm{~T} 124000$ & $20100608 \mathrm{~T} 175000$ & 0.99 & 4.80 & 41.77 & 90 & 310 \\
\hline event01_2 & $20100608 \mathrm{~T} 191000$ & 20100609 T012000 & 1.06 & 26.40 & 45.73 & 150 & 370 \\
\hline event02 & $20100609 \mathrm{~T} 120500$ & $20100609 T 154500$ & 8.37 & 45.60 & 289.11 & 1030 & 220 \\
\hline event03_m & $20100610 T 213000$ & 20100613 T020000 & 1.07 & 12.00 & 77.91 & 880 & 3150 \\
\hline event04_2 & $20100630 \mathrm{~T} 080000$ & $20100630 \mathrm{~T} 160500$ & 1.54 & 12.00 & 47.14 & 120 & 485 \\
\hline event05 & 20100712 T222500 & 20100713 T022500 & 3.67 & 62.40 & 99.59 & 490 & 240 \\
\hline event06_1 & 20100729T070000 & $20100729 T 161000$ & 0.48 & 7.20 & 23.33 & 40 & 550 \\
\hline event06_2 & $20100729 \mathrm{~T} 161500$ & 20100731 T043000 & 0.91 & 26.40 & 47.20 & 160 & 2175 \\
\hline event07_1 & $20100805 \mathrm{~T} 133500$ & $20100805 \mathrm{~T} 212500$ & 1.31 & 36.00 & 37.37 & 140 & 470 \\
\hline event07_2 & $20100806 \mathrm{~T} 000000$ & 20100806 T021500 & 2.40 & 48.00 & 51.43 & 160 & 135 \\
\hline event07_3 & $20100806 \mathrm{~T} 025500$ & $20100806 \mathrm{~T} 181000$ & 0.76 & 14.40 & 44.46 & 170 & 915 \\
\hline event08 & $20100813 T 040500$ & $20100813 \mathrm{~T} 213500$ & 1.23 & 31.20 & 49.34 & 160 & 1050 \\
\hline event09 & 20100913 T204500 & 20100915 T045000 & 0.83 & 24.00 & 36.37 & 130 & 1925 \\
\hline event10 & $20100924 T 084500$ & $20100925 \mathrm{~T} 033500$ & 1.62 & 9.60 & 82.25 & 160 & 1130 \\
\hline event12_m & $20160615 T 201500$ & 20160616 T022000 & 0.44 & 10.80 & 71.35 & 160 & 365 \\
\hline event14_m1 & $20160620 \mathrm{~T} 123000$ & 20160621 T043500 & 1.14 & 6.00 & 72.16 & 160 & 965 \\
\hline event14_m2 & 20160621 T044000 & $20160621 T 072000$ & 1.75 & 15.60 & 125.94 & 450 & 160 \\
\hline event16 & $20160627 \mathrm{~T} 210500$ & $20160628 \mathrm{~T} 040500$ & 0.52 & 6.00 & 55.76 & 110 & 420 \\
\hline event18_1 & $20160701 \mathrm{~T} 115500$ & $20160701 \mathrm{~T} 210500$ & 0.61 & 15.60 & 61.62 & 140 & 550 \\
\hline event18_2 & 20160702 T084500 & $20160703 \mathrm{~T} 012500$ & 0.65 & 20.40 & 75.57 & 280 & 1000 \\
\hline event21_m1 & 20160712 T163500 & $20160712 T 201500$ & 1.12 & 13.20 & 64.00 & 150 & 220 \\
\hline event21_m2 & $20160714 \mathrm{~T} 160500$ & $20160714 \mathrm{~T} 215500$ & 0.56 & 12.00 & 72.68 & 180 & 350 \\
\hline event22 & $20160728 \mathrm{~T} 002000$ & $20160728 \mathrm{~T} 054000$ & 0.63 & 15.60 & 69.08 & 210 & 320 \\
\hline event24 & 20160803 T154500 & $20160804 T 130500$ & 0.88 & 14.40 & 72.72 & 310 & 1280 \\
\hline event 25 & $20160805 T 031000$ & $20160805 \mathrm{~T} 114500$ & 0.70 & 19.20 & 80.96 & 240 & 515 \\
\hline event26_1 & $20160806 \mathrm{~T} 030000$ & $20160806 \mathrm{~T} 073500$ & 0.94 & 12.00 & 70.71 & 130 & 275 \\
\hline event26_2 & $20160806 \mathrm{~T} 084500$ & $20160806 \mathrm{~T} 191500$ & 0.83 & 9.60 & 112.52 & 230 & 630 \\
\hline event26_3 & $20160807 \mathrm{~T} 134500$ & $20160807 \mathrm{~T} 210500$ & 0.66 & 4.80 & 63.93 & 110 & 440 \\
\hline event32 & $20160820 T 222500$ & $20160821 T 011500$ & 4.18 & 22.80 & 94.29 & 460 & 170 \\
\hline event33 & $20160826 \mathrm{~T} 005500$ & $20160826 \mathrm{~T} 100000$ & 0.92 & 10.80 & 94.00 & 270 & 545 \\
\hline event38_1 & 20170809T000000 & 20170809T075000 & 1.40 & 15.60 & 46.74 & 140 & 470 \\
\hline event41 & 20170909T163000 & 20170909T195500 & 2.91 & 22.80 & 320.00 & 840 & 205 \\
\hline
\end{tabular}

There was a high correlation between mean event rainfall and maximum discharge but a low correlation between maximum rainfall and maximum discharge (Table 2). The results show, not unexpectedly, that the total amount of rainfall during an event is more important than the peak rainfall.

Table 2 Pearson correlations between events maximum discharge $(\max Q)$ and mean rainfall $($ mean $P)$ and maximum rainfall $(\max P)$.

\begin{tabular}{ccc}
\hline & $\operatorname{Mean} P$ & $\operatorname{Max} P$ \\
\hline $\max Q$ & 0.72 & 0.37 \\
\hline
\end{tabular}

\subsection{Runoff components}

Sewage is only a small component of the total discharge, but it is the pollutant source of the CSO problem. Figure 4 shows the hourly pattern of wastewater discharge. Sewage has a clear hourly pattern within the day. It increases from midnight to early morning and then decreases, and increases again in the afternoon. There is more wastewater flow on workdays than on weekends. Sewage on weekends is more stable than on workdays after the early morning.

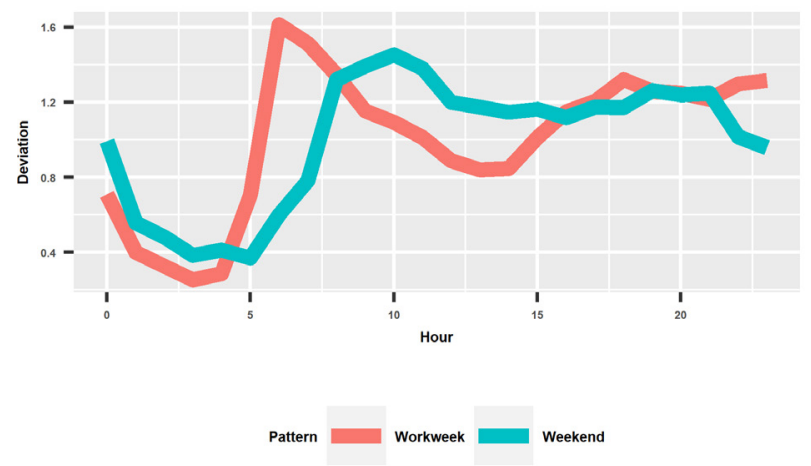

Figure 4 Hourly patterns of wastewater for the workweek (Monday-Friday) and weekend (Saturday and Sunday).

Sewage is a relatively stable component of the total discharge, but it is the source of pollutants. Figure 5 shows the elapsed time of overflow, total discharge, and sewage for the CSO events. There were good linear relationships between the elapsed time and the square root of sewage volume (Pearson correlation 0.95), and elapsed time and the square root of discharge volume (Pearson correlation 0.97) for CSO. The correlation between the square root of sewage volume and the square root of total discharge was 0.99:

$$
\begin{aligned}
& \sqrt[2]{Q / 100}=0.05636 \times \text { time }+0.19854 \\
& \sqrt[2]{W}=0.05462 \times \text { time }+0.12346 \\
& \sqrt[2]{W}=0.97556 \times \sqrt[2]{Q / 100}-0.07605
\end{aligned}
$$

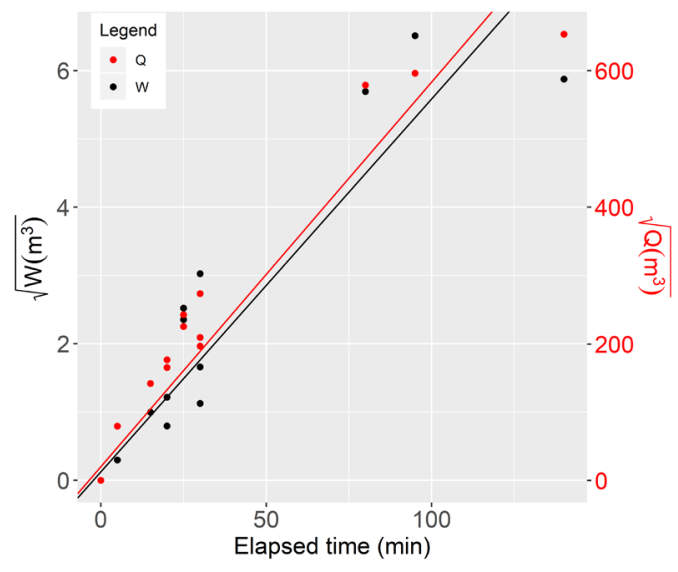

Figure 5 Relation between elapsed CSO time and sewage $(W)$, and elapsed CSO time and total discharge $(Q)$; CSO occurs when $Q>200 \mathrm{~L} / \mathrm{s}$; red dot = total discharge, black dot $=$ sewage. 


\subsection{Calibration}

We calibrated the SWMM model for each rainfall-runoff event and validated the calibrations using the four indicators NSE, PB, $C E$ runoff and $C E$ flow. The calibrations were quite successful in terms of hydrological and hydraulic dynamics, indicated by high NSE and low PB (Figure 6). In terms of computation performance, the values of $C E$ runoff were very low, with all calibrations $<1 \%$. However, CE flow is a critical indicator and only four calibrations were $<10 \%$. The numbers of successful calibrations according to each criterion are tabulated in Table 3. (a) NSE

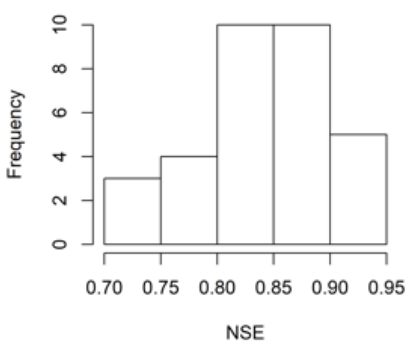

(c) CE runoff

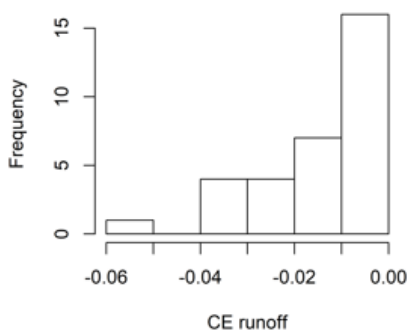

(b) PB

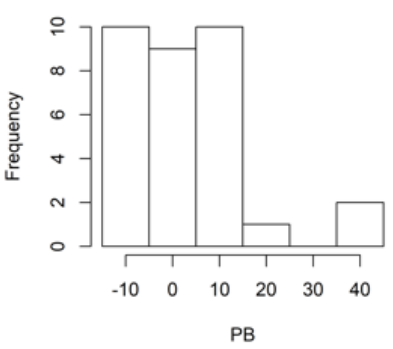

(d) CE flow

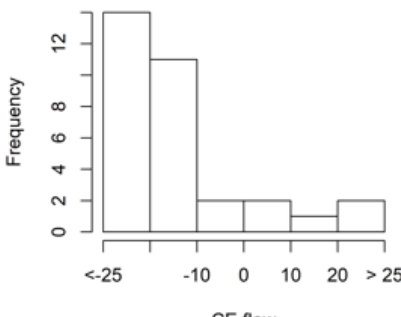

Figure 6 Histograms of the criteria for calibrations: (a) NSE; (b) $P B$; (c) $C E$ runoff; (d) $C E$ flow.

Table 3 Number of successful calibrations out of a total of 32 calibrations for each indicator.

\begin{tabular}{cccc}
\hline NSE & $P B$ & CErunoff & CE flow \\
\hline 32 & 30 & 32 & 4 \\
\hline
\end{tabular}

Table 4 shows the model performance of the four calibration criteria and Figure 7 shows the hydrographs. The calibration for event 3 was the best in terms of NSE, PB and CE flow. The calibration for event12_m was the worst in terms of NSE, $P B$ and $C E$ runoff.

Table 4 Model performance of the successful calibrations.

\begin{tabular}{lcccc}
\hline \multicolumn{1}{c}{ Event } & NSE & $P B(\%)$ & CE runoff (\%) & CE flow (\%) \\
\hline event10 & 0.871 & -8.52 & -0.003 & -7.285 \\
event12_m & 0.705 & 15.10 & -0.036 & 7.664 \\
event14_m1 & 0.862 & -8.78 & -0.006 & -8.557 \\
event33 & 0.938 & -6.24 & -0.013 & 6.665 \\
\hline
\end{tabular}
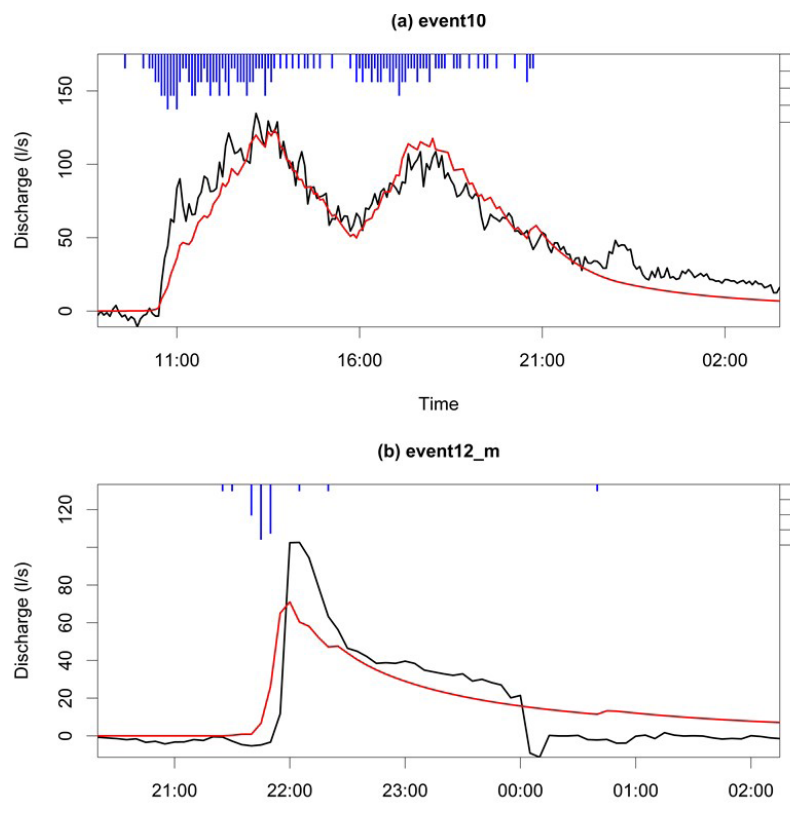

(c) event14_m1
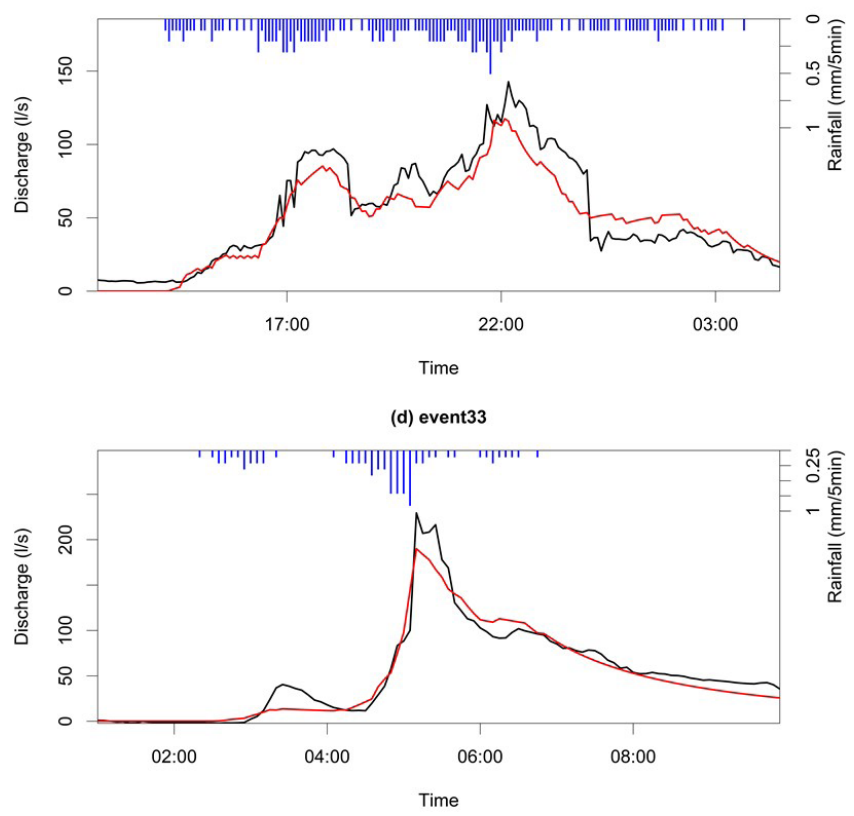

Figure 7 Hydrograph of the successful calibrations; black line $=$ observed, red line $=$ simulated .

\subsection{Validation}

Each successfully calibrated SWMM model was validated on the other 31 events. There were therefore 124 (4 successful calibrations $\times 31$ validations) validation model runs altogether. The four indicators were calculated for every validation. Figure 8 shows the values of the indicators for the validations. Table 5 shows the number of successful validations based on the four criteria. Values of CE runoff for all the validations are within $\pm 10 \%$. NSE, $P B$ and $C E$ flow filter out the successful validations. For model calibration, $P B$ and $C E$ flow were found to be the most critical indicators. 

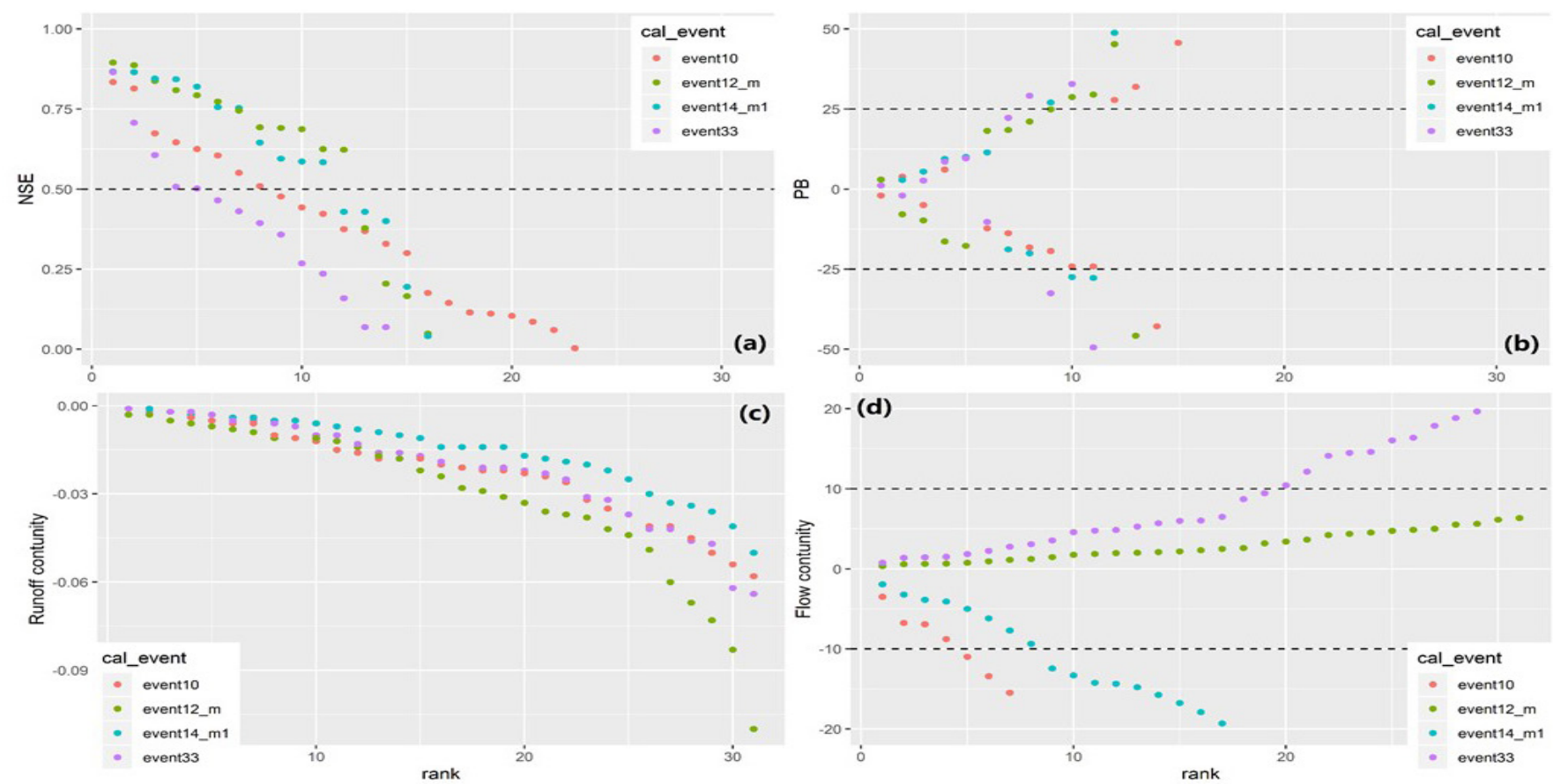

Figure 8 Model performance of the validations: (a) NSE; (b) PB; (c) CE runoff; (d) CE flow.

Table 5 Number of successful validations for each indicator.

\begin{tabular}{lcccc}
\hline \multicolumn{1}{c}{ Event } & NSE & PB & CE runoff & CE flow \\
\hline event10 & 23 & 11 & 31 & 4 \\
event12_m & 19 & 9 & 31 & 31 \\
event14_m1 & 20 & 8 & 31 & 8 \\
event33 & 26 & 7 & 31 & 19 \\
\multicolumn{1}{c}{ Total } & 88 & 35 & 124 & 62 \\
\hline
\end{tabular}

Among the 13 successful validations, two were calibrated using event10, nine using event12_m, and two were calibrated using event33 (Table 6). The calibration using event14_m1 was not successfully validated. It was difficult to determine why event12_m performed best in the validation. Figure 7 shows that the hydrograph of event12_m was the simplest, and there was one peak. Event10 had two similar close peaks; event33 had two peaks, one very small and the other large. Event14_m1 had three peaks that were very close to each other.
Table 6 Successful validations.

\begin{tabular}{llcccc}
\hline Cal_event & Val_event & NSE & $P B(\%)$ & CE runoff (\%) & CEflow (\%) \\
\hline event10 & event02 & 0.625 & 3.9 & -0.1 & -6.9 \\
event10 & event03_m & 0.674 & -19.3 & 0.0 & -3.5 \\
event12_m & event03_m & 0.623 & 21.1 & 0.0 & 0.4 \\
event12_m & event14_m1 & 0.895 & 3.0 & 0.0 & 1.2 \\
event12_m & event16 & 0.625 & 18.2 & 0.0 & 5.6 \\
event12_m & event18_1 & 0.687 & 24.9 & 0.0 & 3.7 \\
event12_m & event18_2 & 0.693 & 18.5 & 0.0 & 2.0 \\
event12_m & event21_m2 & 0.838 & -16.3 & 0.0 & 6.4 \\
event12_m & event25 & 0.887 & -7.9 & 0.0 & 3.4 \\
event12_m & event26_2 & 0.745 & -9.8 & 0.0 & 2.5 \\
event12_m & event33 & 0.793 & -17.7 & 0.0 & 2.6 \\
event33 & event25 & 0.606 & -2.0 & 0.0 & 9.5 \\
event33 & event26_2 & 0.865 & 8.6 & 0.0 & 6.0 \\
\hline
\end{tabular}

Notes: Cal_event: calibration event; Val_event: validation event. 


\subsection{Parameters}

PCSWMM had 56 parameters. We found that 18 parameters affected discharge at the AK52 outfall. Figures 9 through 11 show the calibrated parameters. The most sensitive parameters were those for subcatchment characteristics: area, width, slope, and impermeable percentage. It was difficult to quantify them precisely due to interactions and interdependencies between parameters. For example, a small area can have a large impermeable surface percentage and small infiltration capacity. Although these parameters have clear physical interpretations, they cannot be estimated from measurements. Our experience tells us that it is necessary to calibrate them to get a satisfactory model performance.

The infiltration parameter $K_{\text {sat }}$ (conductivity) was very small compared to measured values, varying from $80 \mathrm{~mm} / \mathrm{h}$ to $4160 \mathrm{~mm} / \mathrm{h}$ (Storteig 2019). The was because our model did not include groundwater, and therefore infiltrated water did not contribute to total discharge at the outfall. The total discharge was largely controlled by the subcatchment area and the percentage impervious area. Infiltration had little effect in this model and infiltration parameters depended greatly on the subcatchment parameters.

The length of the calibration period ranged from $135 \mathrm{~min}$ to $3150 \mathrm{~min}$. The shortest event only had 27 data points with which to calibrate the model. In Figure 9 and Figure 10, many calibrated parameters were still at their initial value (1 in the figures); for example, permeable area roughness and permeable area storage. These parameters were not sensitive to discharge simulation. Besides, there was no strong correlation (only 0.09) between NSE of calibration and calibration period length, and there was no strong correlation between model performance in calibration periods and the lengths of validation periods.

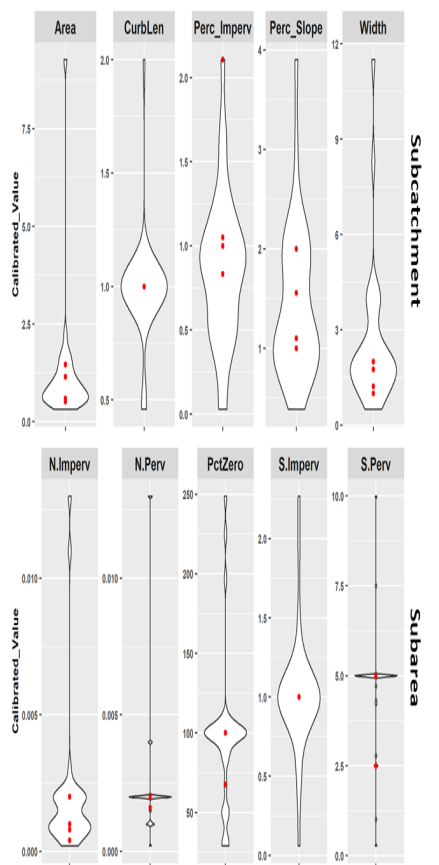

Figure 9 Violin plots of calibrated subcatchment and subarea parameters; the characteristics are for each of the subcatchments; for the subcatchment, the plot presents the ratio of the calibrated value to the initial value estimated from the input data, so 1 indicates that the calibrated value was the same as the initial value; for the subarea, the plot presents the parameter value; red $\operatorname{dot}=$ successful calibration.

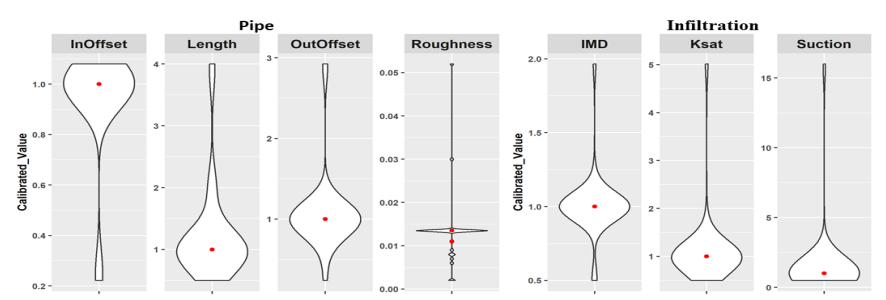

Figure 10 Violin plots of calibrated pipe and infiltration parameters; for the pipe, the plot presents the ratio of the calibrated value to the initial value estimated from the input data; for the infiltration, the plot presents the parameter value; red dot $=$ successful calibration.

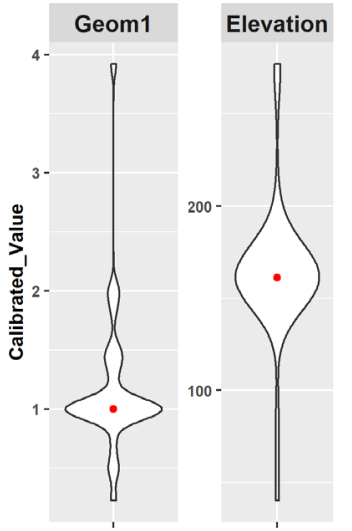

Figure 11 Violin plots of calibrated section (Geom1) and outfall (Elevation) parameters; the plot presents the parameter value; red dot $=$ successful calibration.

\section{Conclusions}

We investigated the applicability of the Storm Water Management Model (SWMM) in a partially separated and partially combined sewer system in the Grefsen catchment in Oslo. We examined parameter sensitivity, the relation between calibration period and performance, and the relation between calibration period length and validation. We calibrated SWMM using 32 events and evaluated the model performance using four indicators: Nash-Sutcliffe efficiency, percentage bias, continuity error for runoff, and continuity error for flow. The number of successful calibrations varied greatly for the different indicators. There were 32 successful calibrations out of 32 using NSE, 30 successful calibrations using $P B, 32$ using $C E$ runoff, and 4 using $C E$ flow. There were only 4 successful calibrations using all four indicators. 
Of the $124(4 \times 31)$ validations, 88 were successful using NSE, 35 using $P E, 124$ using $C E$ runoff, and 62 using $C E$ flow. There were 13 successful validations using all four indicators. The results show large uncertainty due to the calibration and evaluation indicators and highlight the importance of considering model computation error for flow routing when using SWMM.

It is difficult to generalize model parameters due to the uncertainty in discharge measurements and in the sewer network as well as the high heterogeneity among events. More research, including measurements and model experiments, is necessary to assess the performance of this Norwegian urban water system.

\section{Acknowledgments}

We thank the Norwegian research council for funding through the projects New Water Ways: 270742 and DeSCIPHER: 299937. We thank Oslo Municipality Water and Sewage Administration, the Norwegian Meteorological Institute, and the Norwegian Institute for Nature Research and Norwegian Water Resources and Energy Directorate for providing data. We thank Tianjin Longwang Technology Development Limited Company and Hydropraxis for the provision of a PCSWMM license. We thank the reviewers and the editor for their comments and suggestions for improving the quality of this paper.

\section{References}

Åstebøl, S.O., and T. Hvitved-Jacobsen. 2006. Protection of water resources in planning and construction of roads. Oslo: The Norwegian Directorate of Public Roads. Manual 2006: 261.

Department of Environmental Conservation. 2021. Combined Sewer Overflow (CSO). https://www.dec.ny.gov/chemical/48595.html

Digiano, F.A., and P.A. Mangarella. 1975. Application of stormwater management models. Cincinnati, OH: EPA. https://play.google.com/books/reader?id=h4hVAAAAYAAJ\&hl=en_GB\&pg=GBS.PR 1

Farah, J. 2009. SWMM high continuity error in flow routing. https://www.openswmm.org/Topic/3925/high-continuityerror-in-flow-routing

Finsland, W. 2019. Personal communication. Oslo Municipality Water and Sewage Administration.

Hamouz, V. and T.M. Muthanna. 2019. “Hydrological modelling of green and grey roofs in cold climate with the SWMM model." Journal of Environmental Management 249: 109350s

Holmberg, T.H. 2019. Implications for local stormwater treatment and rainwater-use for wastewater treatment in Oslo. https://ntnuopen.ntnu.no/ntnu-xmlui/handle/11250/2622386

Johannessen, B.G., V. Hamouz, A. S. Gragne, and T.M. Muthanna. 2019. "The transferability of SWMM model parameters between green roofs with similar build-up." Journal of Hydrology 569: 816-28.
Lager, J.A., E.E. Pyatt, and R.P. Shubinski. 1971. Storm Water Management Model. Berkeley, CA: U.S. Government Printing Office.

Li, H., H. Gao, Y. Zhou, C.Y. Xu, M. Rengifo, and N.R. Sælthun.

2020. "Usage of SIMWE model to model urban overland flood: A case study in Oslo". Hydrology Research 51 (2): 366-80s.

Lindberg, S., S. Jorgensen, and T. Willemoes. 1986. "MOUSE modelling of urban storm sewer systems." In Proceedings of the International Symposium on Comparison of Urban Drainage Models with Real Catchments, Dubrovnik.

Lindholm O., W. Schilling, and D. Crichton. 2006. “Urban water management before the court: Flooding in Fredrikstad, Norway." Journal of Water Law 17: 204-09.

Mæhlum, G. 2014. LiDAR-repport. Oslo: BLOM.

Niazi, M., C. Nietch, M. Maghrebi, N. Jackson, B.R. Bennett, M. Tryby, and A. Massoudieh. 2017. "Storm Water Management Model: Performance review and gap analysis." Journal of Sustainable Water in the Built Environment 3 (2): 04017002.

Nie, L. 2016. "Enhancing urban flood resilience-A case study of policy implementation." Water Management 169 (2): 85-93 https://doi.org/10.1680/wama.14.00079

Nie, L., O. Lindholm, S.O. Åstebøl, S. Sægrov, and S. Thorolfsson. 2011. "Integrated urban stormwater management in Norway -Best management practices (BMPs) in cold climate." In Proceedings of the 12th International Conference of Urban Drainage to Brazil, Porto Alegre, Brazil, September 11-16, 2011.

Nie, L., O. Lindholm, G. Lindholm, and E. Syversen. 2009. "Impacts of climate change on urban drainage systems-A case study in Fredrikstad, Norway." Urban Water Journal 6 (4): 323-32.

NIVUS, G. 2015. Instruction manual for rain gauge measurement device. www.nivus.com

Norwegian Mapping Authority. 2005. Common maps database (FKB). https://kartkatalog.geonorge.no/metadata/geovekst/ felles-kartdatabase-fkb/0e90ca71-6a02-4036-bd94f219fe64645f

PCSWMM/Computational Hydraulics International. 2020. PCSWMM Sensitivity-based Radio Tuning Calibration Tool https://www.pcswmm.com/

Rossman, L.A. 2015. Storm Water Management Model user's manual version 5.1. Cincinnati, $\mathrm{OH}$ : USEPA Office of Research and Development Water Supply and Water Resources Division.

Rossman, L.A., and W.C. Huber. 2016. Storm Water Management Model user's manual version 5.1. Cincinnati, OH: USEPA Office of Research and Development Water Supply and Water Resources Division.

Russwurm, I., G.B. Johannessen, A. Gragne, J. Lohne, and T.M. Muthanna. 2018. "Modelling green roof detention performance in cold climates." EPiC Series in Engineering 3:1804-13.

Salvadore, E., J. Bronders, and O. Batelaan. 2015. “Hydrological modelling of urbanized catchments: A review and future directions." Journal of Hydrology 529 (P1): 62-81. https://doi.org/10.1016/j.jhydrol.2015.06.028 
Skaugen, T., D. Lawrence, and R.Z. Ortega. 2020. “A parameter parsimonious approach for catchment scale urban hydrolog -Which processes are important?" Journal of Hydrology X 8: 100060.

https://doi.org/10.1016/j.hydroa.2020.100060

SSB. 2018. Population projections-Statistics Norway. 24 (2), 346-60. http://epp.eurostat.ec.europa.eu/statistics_explained/index.php/Population_projections

SSB. 2019. Municipal water supply-Statistics Norway. https://www.ssb.no/en/natur-og-miljo/statistikker/vann_ kostra/aar

Stange E. 2017. Land cover from Sentinel 2-Bærum, Lørenskog, Nittedal, Oppegård, Oslo, Sked.

http://urban.nina.no/layers/geonode\%3As2_oslo_metro

Statista. 2019. Sweden: Urbanization from 2007 to 2017. https://www.statista.com/statistics/455935/urbanization-in-sweden

Storteig, I. C. 2019. Continuous urban hydrological modeling of discharge peaks with SWMM. Oslo: University of Oslo. Masters thesis.
United Nations. 2019. World population prospects 2019. https://population.un.org/wpp/Graphs/Probabilistic/POP/ TOT/900

VAV. 2016. Main report-Strategy for stormwater management in the Oslo municipality. Oslo Municipality Water and Sewage Administration.

https://www.oslo.kommune.no/getfile.php/13174529/ Innhold/Politikk og administrasjon/Slik bygger vi Oslo/Vannområde Oslo/Rapporter og planer/2016 Handlingsplan for overvannshåndtering i Oslo kommune - Hovedrapport. pdf

Velasco, M., L. Nie, and L. Arguelles. 2012. Methodology for urban runoff risk assessment caused by climate change. Summary report for D 5.3.1. Submitted to the EU FP7 project PREPARED_Enabling Change.

Wikipedia. 2021. CSOs in the United States. https://en.wikipedia.org/wiki/Combined_sewer 